\title{
Towards a Better Understanding of Consumer Behavior: Marginal Utility as a Parameter in Neuromarketing Research
}

\author{
Letizia Alvino $^{1}$, Efthymios Constantinides ${ }^{2} \&$ Massimo Franco ${ }^{1}$ \\ ${ }^{1}$ University of Molise, Campobasso, Italy \\ ${ }^{2}$ University of Twente, Enschede, The Netherlands \\ Correspondence: Letizia Alvino, University of Molise, Campobasso, Italy.
}

Received: February 10, 2018

Accepted: February 24, 2018 Online Published: February 27, 2018

doi:10.5539/ijms.v10n1p90

URL: https://doi.org/10.5539/ijms.v10n1p90

\begin{abstract}
Understanding consumers' decision-making process is one of the most important goal in Marketing. However, the traditional tools (e,g, surveys, personal interviews and observations) used in Marketing research are often inadequate to analyse and study consumer behaviour. Since people's decisions are influenced by several unconscious mental processes, the consumers very often do not want to, or do not know how to, explain their choices. For this reason, Neuromarketing research has grown in popularity. Neuromarketing uses both psychological and Neuroscience techniques in order to analyse the neurological and psychological mechanisms that underlying human decisions and behaviours. Hence, studying these mechanisms is useful to explain consumers' responses to marketing stimuli.

This paper (1) provides an overview of the current and previous research in Neuromarketing; (2) analyzes the use of Marginal Utility theory in Neuromarketing. In fact, there is remarkably little direct empirical evidence of the use of Marginal Utility in Neuromarketing studies. Marginal Utility is an essential economic parameter affecting satisfaction and one of the most important elements of the consumers' decision-making process. Through the use of Marginal Utility theory, economists can measure satisfaction, which affects largely the consumer's decision-making process. The research gap between Neuromarketing and use of Marginal Utility theory is discussed in this paper. We describe why Neuromarketing studies should take into account this parameter. We conclude with our vision of the potential research at the interaction of Marginal Utility and Neuromarketing.
\end{abstract}

Keywords: consumer satisfaction, consumers decision-making process, Marginal Utility, Neuromarketing, Consumer Neuroscience

\section{Introduction}

Neuromarketing (NM) is an excellent tool to "read" the customer's mind and address questions about buyer's behavior. Although Neuromarketing research has reached tangible results (Damasio, 1994; Lindstrom, 2008; McClure, 2014; Plassman, 2015), researchers seem to overlook some important economic notions, such as the Marginal Utility, that plays an important role in the consumers' decision-making processes. The goal of this paper is to provide a critical review of literature on "MU + Neuromarketing", to find scientific papers that explain the significant contribution of Marginal Utility (MU) in the Neuromarketing science. The outline of this article is as follows. Firstly, we illustrate how we selected and clustered papers on MU present in chosen databases. Secondly, we provide a brief literature review on MU theory and Law of Diminishing Marginal Utility. Thirdly, we explain our findings. This paper also critically reviews the absence of MU in both theoretical and empirical research in Neuromarketing. We report random and systematic errors found in experiments and the resulting biased results obtained. Finally, we discuss the contributions and implications of our findings for Neuromarketing researchers.

\section{Methodology}

The bibliographic research can be divided in two steps. In the first step, we searched informations about Neuromarketing in blogs and academic articles. The blogs were Neurosciencemarketing and Scientific American. The academic articles were selected searching for Neuromarketing and Marginal Utility in Googles scholar. In the second step, only peer-reviewed academic articles were examined. To access to the content of the articles, 
five different and main platforms were used: Scopus, ScienceDirect, Web of Science, PubMed and EBSCOhost. The papers were selected using keywords: Neuromarketing, decision-making process, Marginal Utility. Since no results were found, we searched for other keywords: Neuromarketing, decision-making process and utility. The research produced results in the following databases: Scopus, ScienceDirect and EBSCOhost. The articles were selected on the basis of the "title" and the "abstract". The papers selected belongs to journals from several domains, where Neuromarketing is a research topic: Neuroscience (Nature Reviews Neuroscience, NeuroReport, NeuroImage Frontiers in Human Neuroscience, Brain Research Bulletin), Marketing (Journal of Marketing Research, Journal of Services Marketing), Psychology (Journal of Consumer Psychology, International Journal of Psychophysiology), Other (Journal of Consumer Protection and Food Safety, Current Biology, Procedia-Social and Behavioral Sciences, Journal of Mechanical Design, Tourism Management) and Conference papers (NeuroPsychoEconomics Conference Proceedings). Firstly, the various journal articles were analyzed and groped in three categories: Review papers, Empirical papers and Concept papers. Finally, papers were clustered into different categories, according to their topics. We identified five clusters: Application to Marketing, Value, Brand and Products, Quality and Reward, and Marginal Utility.

\section{Consumer's Demand and Utility}

The notion of demand has been widely debated and analyzed in economics. The purpose is to identify the factors that affect demand. According to Koutsoyiannis (1979), these factors are the price of a product, customers' incomes and wealth, the prices of other similar commodities, the income distributions and the credit availability. Christensen, Jorgenson, \& Lau (1975) state that the consumer's demand is a system of demand functions; the quantity consumed of each commodity is considered to be a function of the total expenditure and the prices of all commodities (Christensen, Jorgenson, \& Lau, 1975). However, the starting point for these studies is the examination of consumer behavior (Koutsoyiannis, 1979). Understanding the consumer's decision-making process aims at the construction of models, which describe the behavior of individuals. These models assume that decision makers use a set of rational criteria while making a decision, which is considered rational (Tosi et al., 2002). In fact, the consumer is defined as a homo oeconomicus (Mill, 1848), whose main characteristics are rationality and an exclusive care for his own individual interests (Mill, 1848). In the course of time, the term "rational" has come to acquire several different meanings. In the common sense, it is associated with what is "intelligent" or "effective", while in other cases it means "primly materialistic" or even "sane" (March, 1994). In the theory of consumer behavior, rationality implies that the decision-making process is not influenced by individual's personality. This implies the adoption of a systemic analysis of the problem, followed by choice and realization, moving along a precise logic sequence (Daft et al., 2010). If the homo oeconomicus is placed into the market, given his income and the market prices of the different goods, he plans the expending of his income that attains the highest possible satisfaction (Samuelson, 1937). The benefit or satisfaction that a person gets from the consumption of a good or service is called Utility (Cohen, King, \& Parkin, 2000). Samuelson (1937) assumes that the utility function is an additive function of the utilities corresponding to each good (e.g., goods might be very specific, like tickets or much aggregated like food and shelter). Consumers choose between a vector of goods $\mathrm{x}=\left(\mathrm{x}_{1}, \mathrm{x}_{2, \ldots . .}, \mathrm{x}_{\mathrm{n}}\right)$, without exceeding their constraint budget, represented by their total wealth or income (Levin \& Milgrom, 2004). Koutsoyiannis (1979) argued that "the Total Utility (TU) of a "basket of goods" depends on the quantities of the individual commodities". If there are $n$ goods and the quantity of each of them is $\mathrm{X} 1, \mathrm{X} 2, \ldots . . . \mathrm{Xn}$, the Total Utility is:

$$
\mathrm{U}=f(\mathrm{x} 1, \mathrm{x} 2, \ldots . . \mathrm{xn})
$$

The greater the quantity of a good consumed, the higher is the Total Utility from consuming that good (Cohen, King, \& Parkin, 2000). However, how said before all the mathematical representations are formulated considering the homo oeconomicus. Assuming that the utility of each commodity is miserable, the consumer always aims at maximizing his utility (Koutsoyiannis, 1979). The sets of consumers's choices are assumed to be defined by certain prices and the consumer's income or wealth. It is possible to define the consumer problem $(\mathrm{CP})$ as:

$$
\begin{aligned}
& \operatorname{Max} u(x) \\
& x \in \mathrm{R}^{\mathrm{n}}{ }_{+} \\
& \text {s.t. } \mathrm{p} \cdot \mathrm{x} \leq \mathrm{w}
\end{aligned}
$$

This is called axiom of utility maximization.

\section{Marginal Utility}

The concept of Utility is strictly related to the concept of Marginal Utility. The concept of Marginal Utility (MU), 
from the perspective budgetary studies and market behavior, has been investigated by many scientists (Frisch, 1932). The idea can be traced back to ancient Greece, where the philosopher Aristotle was the first to develop the theory, according to Frisch (1932). The-concept of Marginal Utility was proposed by Galiani (1751), who studied the central role of utility and scarcity and. Successively, numerous authors, such as Adam Smith (1776), who based a system of political economy entirely based on Marginal Utility calculation, used and readapted it (Kauder, 1953). The Marginal Utility concept gives answers to different questions: (i) what happens if the consumer buys one more units of the same goods? (ii) How much a consumer's utility would increase for every additional unit purchased?

The Marginal Utility can be defined as the change in utility associated with a small change for one of the goods consumed when keeping the quantity of the other good fixed (Levin \& Milgrom, 2004). It can also be described as "the extra utility received from consuming one additional unit of the good per unit of time while holding constant the quantity consumed of all other commodities" (Salvatore, 2008). The consumer can be considered in equilibrium when the $\mathrm{MU}$ of an $\mathrm{x}$ good is equal to its market price $\left(\mathrm{P}_{\mathrm{x}}\right)$, and described as:

$$
\mathrm{MU}_{\mathrm{x}}=\mathrm{P}_{\mathrm{x}}
$$

If the MU of a good $\mathrm{x}$ is higher that its price, the consumer can buy an extra unit of that good (Koutsoyiannis, 1979). Unlike, the consumer can increase his total satisfaction, reducing the quantity of $x$, when the MU of the good $\mathrm{x}$ is less that its price (Koutsoyiannis, 1979).

It is important to notice that the MU measures the rate of change in utility when the quantity of a good consumed varies (Karaivanov, 2012). It basically reflects the slope of the utility function with respect to changes in that specific good. If the quantity of good 1 changes the MU with respect to good 1 (MU1):

$$
\mathrm{MU}_{1=} \frac{\Delta \mathrm{U}}{\Delta \mathrm{x} 1}=\frac{\mathrm{u}(\mathrm{x} 1+\Delta \mathrm{x} 1, \mathrm{x} 2)-\mathrm{u}(\mathrm{x} 1 ; \mathrm{x} 2)}{\Delta x 1}
$$

It is possible to measure the ratio of change in utility $(\Delta \mathrm{U})$ related to a small change in the quantity of good 1 $\left(\Delta x_{1}\right)$, holding constant the quantity of good 2 (Varian, 2002). The change in utility resulting from a change in consumption in good 1 could be calculate multiplying the Marginal Utility (MU1) by the change in consumption:

$$
\Delta U=M U_{1} \Delta x_{1}
$$

the Marginal Utility thus measures the rate at which consumption units are converted into Utility units, i.e. the "price" of one more unit of consumption in terms of utility units (Varian, 2002; Karaivanov, 2012).

\subsection{The Law of Diminishing Marginal Utility}

Given the above definition of MU, it is reasonable to suppose that the Total Utility that the subject derives from consumption of a good $\mathrm{x}$ usually grows with the growth of consumption (Sylos-Labini, 1982). According to Rothbard (1997), a consumer will value two units of the same product more than once, three more than two, and so on. A bundle of 5 units will be ranked higher than a bundle of 4 units, and so on. It should be clear that the only arithmetic or mathematical relationship between these marginal utilities is a simple ordinal one (Rothbard, 1997). On the one hand, given a certain sized unit, the Marginal Utility of that unit declines as the supply of units' increases. This is the familiar Law of Diminishing Marginal Utility (DMU), developed by Hermann Gossen (1983) in "The Laws of Human Relations" (Dittmer, 2005). The theory of DMU, that Friedrich von Wieser successively defined as "Gossen's First Law", is a psychological concept that asserts as more of a good is consumed, each unit provides less additional satisfaction (Dittmer, 2005; Frijtersa \& Leighb, 2008; Kishtainy et al., 2012). According to Brewer and Venaik (2009), the theory of Diminishing Marginal Utility states that the more of a good a person consumes; the less preference they will accord to having more of it. Hence, DMU describes the reduced value that additional units of money or consumer goods have in comparison to units acquired earlier (Diener, Ng \& Tov, 2009). Alfred Marshall (1890), one of the most famous economist of his time, defined the law of Diminishing Marginal Utility as: "The additional benefit which a person derives from a given increase of his stock of a thing diminishes with every increase in the stock that he already has" (Chand, 2016). 
Table 1. Total and Marginal Utility

\begin{tabular}{llll}
\hline Q & $\begin{array}{l}\text { Total and Marginal Utility } \\
\text { Quantity good }\end{array}$ & Total Utility & Marginal Utility \\
\hline 0 & 0 & 0 & $\ldots$ \\
$\mathrm{Q}_{1}$ & 1 & 10 & 10 \\
$\mathrm{Q}_{2}$ & 2 & 16 & 6 \\
$\mathrm{Q}_{3}$ & 3 & 20 & 4 \\
$\mathrm{Q}_{4}$ & 4 & 22 & 2 \\
$\mathrm{Q}_{5}$ & 5 & 22 & 0 \\
$\mathrm{Q}_{6}$ & 6 & 20 & -2 \\
\hline
\end{tabular}

Table 1. The fist column indicates the quantity of the good consumed. The third column gives the extra or Marginal Utility resulting from the consumption of each additional ice-cream. The total and Marginal Utility remains stable with the consumption of the 5th ice-cream. After the 6th ice-cream, TU declines and so MU is negative.

It is possible to find numerous cases of it in everyday life. For instance, considering that the consumption of one ice-cream per day (or, simply, one unit of good X per period of time) gives the consumer a Total Utility of 10 utils, where a util is an arbitrary unit of utility (Salvatore, 2008). The Total Utility increases with each additional unit consumed until the fifth one, which leaves Total Utility unchanged (Salvatore, 2008). Consuming the sixth ice-cream leads to a decline in Total Utility because of storage or disposal problems (Salvatore, 2008). The quantity $\mathrm{Q}_{4}$ of the commodity is called satiation quantity or satiety point (Singh, 2016). In the same way, until the fifth ice-cream the Marginal Utility is positive but declines and becomes negative for the sixth ice-cream (Salvatore, 2008).

It is possible to affirm that the Total Utility does not grow at a constant rate. In fact, the first derivative of the Total Utility (the Marginal Utility) is decreasing (Sylos-Labini, 1982). Therefore, while the Total Utility increases normally with increasing amounts of disposable good, the Marginal Utility decreases (Sylos-Labini, 1982).

\section{Marginal Utility of Neuroscience}

As discussed in the previous section, consumers' decision-making process can be interpreted as choosing alternatives with the goal of maximizing utility (Sanfey, Loewenstein, McClure, \& Cohen, 2006). Maximal utility theory is applicable to a wide range of problems, however, it cannot explain how a consumer evaluate, judge and choose a particular product. In fact, the value of a good is not determined by its maximal utility but Marginal Utility (von Neumann \& Morgenstern, 1947). Economists use MU to measure consumers' satisfaction, and how that affects consumers' decisions. However, other disciplines like Neuroscience and Psychology try to explain the neural bases of decision-making process and value. Neuroscience research has already investigated the brain structures involve in economic decision-making (Platt \& Glimcher, 1999; Padoa-Schioppa \& Assad, 2006; Kable \& Glimcher, 2007; Tobler, Fletcher, Bullmore, \& Schultz, 2007; Kobayashi \& Schultz, 2008; Kim, Hwang, \& Lee, 2008; Levy \& Glimcher, 2011). Today, neuroscientists and psychologists have focused their attention on how brain activity can be realted to Utility and value. Roger Dooley (2007) and the Scientific American (2007), reported one study involving the concept of Marginal Utility in Neuroscience research. Researchers at the University of Cambridge in England tried to assess whether wealthier people catch on more slowly than the less wealthy when it comes to reward-based learning (Tobler, Fletcher, Bullmore, \& Schultz, 2007). During the experiment, a number of different shapes were presented in front of the fourteen participants and observed whether they could accurately predict the next card. After each shape appeared for three seconds, a picture of either a 20-pence coin (approximately 40 cents) or a scrambled image followed. A card of one particular shape was always followed by the coin, and subjects were told that they could take a 20-pence piece home whether they could accurately predict when the money card was the next one up (Swaminathan, 2007). The study revealed that when a small sum of money is on the line, have-nots learn quickly how to maximize their profits, leaving their wealthier counterparts in the dust (Swaminathan, 2007; Dooley et al., 2007); it was possible to track an inverse association between wealth and learning. In fact, the brain activity, in the midbrain and striatum, was increased in poor people compared to reach people (Swaminathan, 2007). The poorer people tended to figure out which card signaled money ahead within about 12 trials, whereas the richer people took about 35 trials (Swaminathan, 2007). The papers showed the fundamental behavioral variable of Marginal Utility, for choices under risks. The experiment also has generated mixed opinions on the world-web. The American author Jonah Lehrer (2007) at The Frontal Cortex supported the thesis, meanwhile, The Economists View found fault with the approach used in the research. 
We found that two more studies investigated the connection between Marginal Utility and neural mechanisms. In the first study, Pine, Seymour, Roiser, Bossaerts, Friston, Curran, \& Dolan (2009) develop a paradigm based on intertemporal choice and varying monetary rewards, to measure direct changes in Marginal Utility. The authors try to describe human preferences integrating temporal discounting and Marginal Utility in a unified model. In the experiment, authors tested the efficiency of this model in accounting for subjects' choices compared with the standard models. Due to this model, they could analyze the brain activity during a task performance by constructing predictor variables to explore the representation of three key quantities. The first two quantities were undiscounted utility (which incorporates the nonlinear utility function but ignores time) and the discount factor (the proportion by which utility is reduced in relation to an immediate payoff, i.e., a value between zero and one). The third quantity was discounted utility (the utility of some future events), it can be considered the product of the first two and it is calculated as the present discounted value of future utility. These variables were generated from the behavioral parameter. Subjects' choices were used to assess the extent of discounting for both magnitude and time. Given the discount factor (D), value between 0 and 1 , and the undiscounted utility (U), the function for the discounted utility (subjective value) of a delayed reward (V) is equal to DxU. D is a function of delay to the reward, and includes the individual's discount rate parameter. Instead, the undiscounted utility is a function of the level of the reward and includes a subject's specific parameter determining the degree of diminishing Marginal Utility.

Functional magnetic resonance imaging (fMRI) was used to record the participant's brain activity. The subjects were asked to choose between two presented options of different amount of money (from £1 to £100) and delay (from 1 week to 1 year). These choices were often smaller-sooner versus larger-later in nature and presented consecutively. The results suggested that the activity in the dorsal striatum encodes both the Marginal Utility of rewards, over and above that which can be described by their magnitude alone, and the discounting associated with increasing time. For example, undiscounted utility $(\mathrm{U})$ is found to be correlated with activity in the striatum, ventral tegmental area (VTA), and anterior cingulate cortex (ACC). The discount factor (D) is correlated to activity in the striatum, insula, posterior and pregenual cingulate cortex, ventromedial orbitofrontal cortex. The authors tested the interaction between variables (i.e., discounted utility, $\mathrm{V}=\mathrm{DxU}$ ) and found significant correlation in the activity of dorsal striatum and pregenual cingulate cortex. Critically, this activation in the dorsal striatum incorporated the same anatomical zone as that of the independent activity measured with both undiscounted utility and temporal discounting. The paper suggests that, given high and low discounts, the concavity or convexity of the function is correlated by with impulsiveness of each individual. The results provide both direct behavioral and neurobiological support for Marginal Utility theory in the context of a choice model that incorporates temporal discounting (Pine et al., 2009).

In the second study, Stauffer, Lak, \& Schultz (2014) found that there is a connection between brain and neurotransmitters activity and the MU theory. Unlike the previous study (Pine et al., 2009), that have mostly used risk preference tasks (such as simple gambles to construct the utility function), this study showed that it is possible to find a correlation by simultaneously administering risk preference, intertemporal choice, impulsivity and utility. Authors (2014) conducted an experiment on monkeys to demonstrate that dopamine prediction error responses represent a neuronal correlate for the fundamental behavioral variable of Marginal Utility. Defining utility as a function of physical value, and using risky choices, authors tried to investigate whether dopamine reward responses reflected the Marginal Utility calculated from the utility function. In fact, risk exerts has an important influence on utility; it enhances utility in risk seekers and reduces utility in risk avoiders. Stauffer, Lak, \& Schultz (2014) tried to assess the animals' risk attitudes, measuring the amount of safe reward that led to choice indifference ("certainty equivalent," $\mathrm{CE}$ ), for a low and high expected value (EV) gamble. The results showed that in both animals, the amount of juice was influencing the behavioral utility function measured in both the monkeys from CEs of binary. The functions were convex when the juice amounts were low (indicating risk seeking) and became linear (risk neutral) and then concave (risk avoiding) as juice amounts increased. Where the utility function was convex, the animals consistently selected riskier options, and where the utility function was concave the animals consistently selected the less risky options. The relationship between the risk attitudes and the curvatures of the utility functions confirmed and substantiated the risk attitudes derived from comparison of CEs with EVs. Moreover, authors investigated the coding of Marginal Utility by dopamine responses to reward prediction errors, defined as reward-prediction. They found that the dopamine responses appeared to reflect the expected utilities derived from the measured utility function, rather than the probability or the EV of the gambles. Importantly, the dopamine utility responses to the cue did not code risk independently of value; the responses were similar between a gamble with considerable risk and a safe reward when the two had similar utility. Thus, the behavioral and neuronal responses demonstrate that the dopamine neurons meaningfully incorporated risk into utility and suggested that dopamine neurons support the economic behavior of the animals. The results suggest that 
exists a common neuronal basis for fundamental explanatory constructs in animal learning theory, such as prediction error, and Marginal Utility.

\section{Analysis of Neuromarketing Literature: Toward an Understanding of Consumer Decision-Making Process}

Neuromarketing (NM) emerged in the early 2000s as a new and popular topic in academic studies. According to Fish et al. (2010), the earliest report on Neuromarketing can be dated back to June 2002 by an advertisement firm, the BrightHouse. The company announced the creation of a business division using fMRI for Marketing research (Fish et al., 2010). The topic of Neuromarketing is a wide-ranging and multidisciplinary topic. Different definitions of Neuromarketing can be found. Neuromarketing can be classified as a research field, a field of Neuroscience and a part of Marketing. It can be considered as a scientific approach, a subarea of Neuroeconomics and a distinct discipline (Fortunato et al., 2014). Authors, like Plassman et al. (2010), Plassman et al. (2015), Venkatraman et al. (2012), prefer to use the term Consumer Neuroscience for academic purposes. Understanding consumer behavior and how consumers make choices during the purchase process is of primary interest in Neuromarketing research (Fortunato et al., 2014). Neuromarketing pioneers as Pinker \& Smidts (2002), Georges, Bayle-Tourtoulou, \& Badoc (2013) and Montague (2014) have investigated and proved how Neuroscience can be an important complement to research and practice in Marketing.

In this section, we review previous work in Neuromarketing research to understand if there is a correlation between Marginal Utility and Neuromarketing research. We first illustrate the main topic discuss in Neuromarketing research regarding consumers' behaviors. We structured the review grouping the papers in five different categories, according to the content of the papers. We identify that main topic in Neuromarketing research are: (1) application to Marketing, (2) brand and products, (3) reward and (4) quality and value.

\section{(1) Consumers' decision making and application to marketing}

Recent years have seen an explosion in the use of neuroimaging techniques to market research. Medical diagnostic devices that allow real-time measurements of brain activity (such as fMRI and EEG) are used in Neuromarketing research. These tools provide information of the brain activity based "on changes in ion polarity, temperature, and electronic impulses" (Fugate, 2008). Neurotransmitters and hormones play a major role in the generation and modulation of various cognitive and behavioral functions that can influence customer satisfaction and loyalty (Koc $\&$ Boz, 2014). Measuring biological factors, such as photoperiod and circadian rhythm, or changes in the secretion or discharge of neurotransmitters and hormones (such as serotonin, dopamine and melatonin) has significant potential implications for Marketing, especially for the tourism and hospitality sectors (Koc \& Boz, 2014). These data remain insensitive to the types of biases that often characterized traditional marketing research (Ariely \& Berns, 2010). For this reasons, Neuromarketing can give a more accurate and objective indication of the underlying preferences of consumers (Ariely \& Berns, 2010). Some authors argue that Neuromarketing research could be considerably broader than the study of consumers' satisfaction and decision-making processes.

Lee, Broderick, \& Chamberlain (2006) suggest that Neuromarketing can be used to assess problems in organizations, like trust, negotiations and pricing. However, we found that the most promising contribution that Neuromarketing can offer is a better understanding of behavioral phenomena relevant for consumer behavior and Marketing (Fugate 2008; Ariely \& Berns, 2010). Mostly studies on NM research try to explain and describe the neurobiological substrate of choice in consumers (Ariely \& Berns, 2010; Vlăsceanu, 2013). There are several ways in which the study of consumers' behaviors in NM can contribute to Marketing. For instance, Kenning and Linzmajer (2010) dispute that emotions and unconscious processes playing a central role in generating behavior. The study of the emotional responses can be applied to all the predominant and essential elements of marketing-mix such as product, price, communication, and distribution policies (Kenning \& Linzmajer, 2010). The authors argue that the approach (i) can help researchers to understand how costumers experience Marketing stimuli positively or negatively; (ii) Neuromarketing can overcome the existing lack of theory in communication research, understanding how the brain processes, learns, and stores advertising stimuli. In distribution policy, the use of emotional reinforces (positive experiences) can constitute the base for sustainable, long-term customer retention. Moreover, it is possible to use Neuroscience tools to determine the optimal price of a product. For example, Knutson et al. (2007) examined the neural correlates of the negative price effect. The activation of the insula corresponds to excessive prices, and the activation of the medial prefrontal cortex is correlated with reduced prices. Bizer \& Schindler (2005) suggest that individuals pay less attention to later numbers in a sequence, for example when the prices end in 0.99 rather than a whole number. These findings can be used to determine how much a customer is willing to pay for a product. NM can be also used to determine the optimal design of a product according to the real preferences of consumers or how the brain responds to differently designed goods. NM 
studies suggest that specific areas of the brain, such as the nucleus accumbens, is correlated with product preferences. However, Ariely \& Berns (2010) argue that usually researches focus on post-design application. The authors suggest that the real pay-off come during the design process. In fact, Neuromarketing can be used for different purposes in marketing process like advertising, early product design, food products, entertainment but also in architecture and political campaigns.

Venkatraman, Clithero, Fitzsimons, \& Huettel (2011) identify six different ways in which Neuroscience can help to improve the prediction of consumers' choises: Testing prototypic ideas and concepts; Developing the physical product; Communicating product information; Understanding user experience; Segmenting consumers for effective Marketing; Building models to predict consumer behavior. In fact, Neuroscience tools can provide information about differences across individuals in the absence of observable differences in behaviors (Venkatraman et al., 2011). Identifying different processes is useful for clustering of consumers based on how they make choices. For instance, if one consumer recalls several memories to make a choice and another simply chooses impulsively, two different strategies can be planned to communicate and meet their needs. One role of NM is to specify brand traits that correspond to preference (Venkatraman et al., 2011). Consumers may be unwilling or unable to express their true preferences. Neuroscience can study emotional and nonconscious processes and construct reliable indices, which could develop concept analysis, and improve the predictions of consumers' preferences (Venkatraman et al., 2011). Moreover, in the development of a product, Neuroscience is important to identify the components, both psychological and neural, that contribute to brand preferences (McClure et al., 2014). During product development, it is possible to identify applications that are useful at other stages, such as neural signatures for taste preferences and neural responses to prices (Knutson et al., 2007; Plassmann et al., 2008). Differentiating the types of subjective experience, it is possible defining the utility theory, in particular the concept of subjective value (SV). In fact, SV allows identifying similarities between brain regions associated with expectation and experience (Venkatraman et al., 2011). Researchers can use SV to target customers into different segments. Neuroscience data can help the segmentation process through its ability to inform individual differences and variability in decision-making process. Finally, Neuroscience can be used to generate out-of-sample applications (Venkatraman et al., 2011). Traditional methods, such as focus groups and surveys, cannot adapt easily to new situations, for instance if the choice environment differs significantly (e.g., time, location). However, a biological model that is based on understanding of behavior and underlying neural mechanisms, which likely will not change from one decision environment to the next, might be less effected by new situations (Alvino \& Franco, 2017; Bernheim, 2009; Clithero et al., 2008).

Other authors like Plassmann, Venkatraman, Huettel, \& Yoon (2015) classified 5 different ways in which NM contributes to Marketing and Customer Behavior. Specifically, NM can identify mechanisms and help to verify and improve existing Marketing theories by providing insights into the underlying mechanism, such as study of self-control failures (Plassmann et al., 2015). As discussed before Neuroscience can help Marketing to measure implicit process. Neurosciences data provide information that is not simple to find due to moral consequences or because the customers do not know why they are a specific behavior or preferences (Plassmann et al., 2015). Moreover, NM can prove dissociations between physiological processes. For instance, neuroimaging tools can differentiate if two different kinds of decisions involve similar or different neural processes and thus they implicate similar or different psychological processes (Plassmann et al., 2015). NM can also be used to understanding individual differences. The use of fMRI data combined with results from surveys and other traditional methodologies, allow researchers to develop a new scale for assessing salespeople's interpersonal metalizing skills (Plassmann et al., 2015). These authors stated the "incorporating neural measures into decision-making models can improve predictions of marketing-relevant behavior" (Plassmann et al., 2015, p. 3). The activation in relevant brain regions can help to predicted consumer behavior and decision-making process. Recent studies have applied Neuroscience methods to predict population level real-market data for music albums' commercial success or smoking cessation hotlines (Berns \& Moore, 2012; Falk, Berkman, \& Lieberman, 2012).

Marketing research has always been focused on how consumers make decisions (Bercea, 2012). However, Neuromarketing has contributed to a systematic understanding of how consumers assess or evaluate items (Plassmann et al., 2015). We do not expect that the use of Neuroscience tools can replace traditional approaches to understand consumer needs (Keller, 2008). However, Neuroscience tools could improve the efficiency of Marketing strategies (Venkatraman et al., 2011). According to Kenning \& Linzmajer (2010), the use of Neuroscience techniques in Marketing is a "win-win situation for both consumers and companies". Neuromarketing contributes to create the effective markets for goods and services that lead to economic growth without reducing the decisive autonomy of consumers (Kenning \& Linzmajer, 2010). 


\section{(2) Judging products and brands}

Neuroscience research can play a useful part in any aspects of Marketing (Ariely \& Berns, 2010), in particular it can help to understand underlying processes involved with brand decisions and products (Plassman et al., 2011; Bercea, 2012). Recent studies investigate neural processes behind multi-attribute decision making and the specific brain functions associated to the presentation of various Marketing stimulus in a consumer-based product evaluation context (Fugate, 2008; Andrejevic, 2012; Goucher-Lambert, Moss, \& Cagan, 2016). We found that previous studies investigated the impact of intangible features (such as aesthetics or luxury) on neural processes. A recent fMRI study examined the differences in affective processing for consumers confronted with aesthetic packaging design compared to standardized packaging (Reimann, Zaichkowsky, Neuhaus, Bender, \& Weber, 2010). The results showed that the view of aesthetic packages elicited affective processes the most, resulting in increased reaction times and engagement of specific affective brain areas (Reimann et al., 2010). Participants took considerably longer to choose aesthetic products than standardized ones. According to the authors, longer reaction times were expected for intense emotional responses, such as aesthetic design. Furthermore, brain areas of the reward system, such as nucleus accumbens and the ventromedial prefrontal cortex, were active when experiencing aesthetic package design (Reimann et al., 2010). In fact, the reward value, defined as the positive value an individual ascribes to an object or behavioral act (Wise \& Rompre, 1989), played an important role in aesthetic product experiences. Finally, they found that a paper-and-pencil measure of affective product involvement was positively related to aesthetic product experiences in the brain (Reimann et al., 2010). These findings suggest that particular packaging or brands (when the success of a specific brand relies on its unique packages) raise different brain responses. However, other tools, such EEG, can be used to measure brain activity. A more recent study by Pozharliev, Verbeke, Strien, \& Bagozzi (2015) provided substantial evidence of dissimilar neural processes when people view luxury (high emotional value) versus basic (low emotional value) branded products. In particular, the authors tested the changes in ERP amplitudes in three time windows (P2, P3, and LPP) during the exposure to pictures of luxury versus basic branded products. In addition, they examined how the perception of luxury brand changed between two conditions, thus the person was alone in the room or together with another participant (Pozharliev et al., 2015). The results showed that different brain responses occurred in the two conditions for the P2 and P3 components over visual cortex sites (Pozharliev et al., 2015). When two participants were in the same room, the LPP amplitude was higher for luxury than for basic branded products, suggesting that LPP amplitude was enhanced by the presence of another person (Pozharliev et al., 2015). Authors argued that LPP amplitude, related to Marketing stimuli with higher emotional value, reflects increased attention allocation and motivational significance, both enhanced by the presence of another person. This experiment shows that NM is a useful instrument that can describe the preferences of consumers for products.

As previously suggested to Fugate (2008), NM can be applied to all form of product in Marketing. Moreover, the author argued that it could be applied also to service. It is important to measure service quality since it has a significant impact on customer satisfaction (Liat, Mansori, Chuan, \& Imrie, 2017). However, the intangible nature of services is extremely difficult to measure and the traditional product-based explorations of consumers' decision-making are inappropriate for intangible purchases (Fugate, 2008). Moreover, Neuromarketing can be used also to predict the success of intangible assets as movie trailer. Using EEG, Boksem \& Smidts (2015) investigated how neuroscientific data provide unique information beyond stated preference measures, in order to predict individual choice behavior and population-wide commercial success. The results of the experiment showed that high-frequency components of the EEG (beta and gamma oscillations), beyond stated preference measures, provide information about participants' individual preferences. Based on the assumption that the medial-frontal beta power is related to individual preference, the authors found that high ranking of a particular movie was related to increase in the amplitude of EEG oscillations in the beta frequency range during viewing of the same movie trailer (Boksem \& Smidts, 2015). Moreover, they found a relationship between commercial success of the viewed movies and very high frequency oscillations in the gamma range, with a frontal and a somewhat bilateral distribution. Gamma bands were related to population preference independent of stated preference measures (Boksem \& Smidts, 2015). These results provided the first evidence that EEG measures are related to real-world outcomes and that these neural measures can significantly add to models predicting choice behavior relative to models that include only stated preference measures (Boksem \& Smidts, 2015).

Finally, we discuss a more recent study by Goucher-Lambert, Moss, \& Cagan (2016). The authors, used fMRI to measure how preference judgments can be altered if sustainability is added as a variable during product choice evaluations. Participants were asked to express their preferences for various water bottles, according to different parameters like forms (high utility, medium utility, low utility), function (material: aluminum, hard plastic, soft 
plastic), and price (\$9.99, $\$ 14.99, \$ 19.99)$. Two different conditions were used: control and environmental. The only difference between the two conditions was that in the second one, calculated environmental impact values for each configuration were included (Goucher-Lambert et al., 2016). The data showed that, during the environmental condition, the importance for form and price attributes decreased. In addition, the importance of functional product attributes increased under these same conditions Goucher-Lambert et al. (2016). The fMRI data showed that brain regions involved in vision and visual processing, such as the inferior occipital gyrus, precuneus and cuneus, were more active during the control condition compared to the environmental condition Goucher-Lambert et al. (2016). It supported the hypothesis that individuals put more mental effort in trying to capture and analyze form information when the environmental impact was not a preference decision attribute. On the other hand, authors underline that there are some aspects of the decision-making process that may have required less mental effort for participants during the Environmental condition (Goucher-Lambert et al., 2016).

Taken together, these findings suggest to us that Neuroscience data help to uncover unique features of preference judgments for products, brand and service that would be impossible to obtain any other way. Neuromarketing can be applied to extend our understanding of how consumers evaluate and judge brands and products.

\section{(3) Brain Reward System}

Neuroscience research spaces from the study of single cells to different brain areas or complex brain systems and how they interact each other (Plassmann, Ramsøy, \& Milosavljevic, 2012). Neuroscience knowledge can be used to understand how individuals behave during positive stimuli (food, cultural goods or money), and which are the reward mechanisms involved during the exposition to such stimuli. In fact, rewards are biological or cognitive stimuli that produce and reinforce approach behaviors (Naranjo, Tremblayi, \& Busto, 2001). We found that the study of the brain reward system (BRS) has a major role in Neuromarketing research. According to Naranjo, Tremblayi \& Busto, 2001 "the BRS consists of extensive neural pathways that mediate reward or reinforce behaviors such as pleasure and motivation". The BRS involves a circuit including the striatum, the orbitofrontal cortex and the amygdala but also the medial prefrontal cortex, in particular the anterior paracingulate cortex (Walter, Abler, Ciaramidaro, \& Erk, 2005). The main function of this system is to direct the individual's behavior toward goals that are normally beneficial. Walter, Abler, Ciaramidaro, \& Erk (2005) argue that our knowledge about reward processing was mainly based on animal research.

Nowadays, numerous studies have been conducted on the reward system in humans with neuroimaging methods. One of the first study of Breiter et al. (1997) shows how cocaine effects the reward system. The results provided evidence of dynamically changes in brain networks associated with cocaine-induced euphoria and cocaine-induced craving (Breiter et al., 1997). However, we found that the study of the reward system is also engaged in economic decision-making (Walter et al., 2005). For instance, in 2002, Erk, Spitzer, Wunderlich, Galley \& Walter carried out an experiment to determine the level of attractiveness of sports cars compared to small cars. The results show that the more attractive the cars, the greater the activation in right ventral striatum and medial orbitofrontal gyrus, as well as in left anterior cingulate cortex, bilateral dorsolateral prefrontal cortex, right fusiform gyrus and left occipital cortex (Erk et al., 2002). Moreover, the experiment of Sanfey et al. (2003) on the Ultimatum game show that punishment is altruistic from an evolutionary point of view, because it involves costs for the punisher. Instead, in 2005, Walter et al. described the results of game theory studies on cooperation and punishment, in online-designs research. The data showed that the cooperative social interaction activates the core structures of the reward circuitry whereas non-cooperative behavior did not. Three main results emerged from these studies. Firstly, the anterior insula is involved when people experience negatively rated social events, like being treated unfair, being frustrated, being socially excluded, or seeing other people suffer. Thus, mental pain seems related to bodily pain in neuroanatomical terms. Secondly, these emotional reactions can be influenced and controlled by regions of the prefrontal cortex. Thirdly, punishment measurements are related to experiencing reward. According to Walter et al. (2005) the main implications of the research on reward in NM is a better control or influence of ourselves. In fact, affective involvement can be used to explain emotions, moods, and feelings evoked by a product. Based on these theoretical assessments, the theory of reward can be used to predict and influence individuals' preferences. Finally, as discussed in section 6.1, the study of Reimann et al. (2010) showed that the key areas of the reward system in the brain, such striatum, nucleus accumbens, and the ventromedial prefrontal cortex, were significantly more activated during affective involvement (aesthetic product package design). It means that the reward system is more engaged when attractive products are presented.

Recently, Breiter et al. (2014), focused on the model of choice, which is centered on how consumers assess reward/aversion. According to the authors, the process of influence is determined by internal (e.g., individual) and external (e.g., group, price) gradients of preference (Breiter et al., 2014). The combination of intrinsic and extrinsic motivations, can help in determining the gradients of individuals' preferences based on the experienced utility 
(Breiter et al., 2014). The authors argued that in NM studies often there is no clear correlation between internal and external motivation, their effects on behavior and how they can shift the distributions of choices. However, we found that some studies focused on how people's individual expectancies shape consumption experiences and how it these experience influence the BRS.

Plassmann \& Weber (2015) tested brain processes, during consumption, on the base of marketing-based expectancy, also defined as "marketing placebo effects" (MPEs). Authors tried to determine how personality traits moderate the placebo effects of price in behavioral experiments of wine tasting. Based on existing evidence that links each of these brain areas with personality traits (i.e., the striatum with reward seeking, the posterior insula with somatosensory awareness, and the dmPFC with need for cognition), they found that that higher gray matter volume in the striatum was linked to higher MPEs responsiveness and also that striatal activity has been linked in overlapping regions to reward seeking (Beaver et al., 2006; Schweinhardt et al., 2009). Plassmann \& Weber (2015) experiment provide evidence that participants high in reward seeking and need for cognitive processing were more responsive to MPEs, whereas those high in somatosensory awareness were less responsive to MPEs. Moreover, the authors replicated the findings from the previous study. In another study they examined if reward responsiveness, somatosensory awareness, and need for cognition moderate the effects of the perceived expertise of artists on subjective aesthetic experiences. They tested the effect of a different cognitive cue (if an art piece was generated by an artist or the experimenter on a computer) on a consumption experience in a different sensory domain (experienced aesthetic pleasantness). The results showed that reward-seeking and motivational behavior play an important role in MPEs. Furthermore, the authors proved that MPEs effects hold for different types of expectancy effects (such an artist's expertise) and sensory domains (aesthetic consumption) and it is not only related to pricing or health claim effects on food consumption.

Expectations and reward have such a powerful influence on consumers that can influence consumption choices and behaviors. However, it is not easy to determine how consumers assess reward and aversion. Taken together, these findings suggest that the evaluation process of rewards has been broadly studied in Neuromarketing. For these reasons, neuroscientific tools can provide information about consumer preferences or, eventually, buying behaviors in real life (Walter et al., 2005).

\section{(4) Quality and Value: keys factor in consumers' satisfaction}

Customers' satisfaction has received great attention to organizations and researchers alike. In order to create and maintain long-term customer relationships, companies have to provide superior value to customers (Ravald \& Grönroos, 1996). However, customer satisfaction is more than a perception of the quality received, it must be taken into account as well the customer's need of quality improvements and his willingness to pay for it (Ravald \& Grönroos, 1996). To establish and maintain mutually beneficial customer relationships, there are several questions that researchers have to address "How can value and quality be defined? Is it possible to measure these components?". Neurosciences tools can provide useful information on how we predict, experience and remember quality and value of products or brand. According to Plassmann, Ramsøy, \& Milosavljevic (2012), "the predicted value represents the consumer's belief about the experienced value of that brand at some time in the future". Specifically, it can be defined as the consumer's belief about how much enjoyment he/she will derive from consuming a product of that specific brand (Plassmann, Ramsøy, \& Milosavljevic, 2012). Authors suggest that at least three brain structures are involved in the evaluation of the predicted values: the striatum, the ventral medial prefrontal cortex (vmPFC), and the dorsolateral prefrontal cortex (dlPFC) (Plassmann, Ramsøy, \& Milosavljevic, 2012). Two studies investigated how favorableness of brand associations affects predicted value signals in the striatum. In the first one, Schaefer \& Rotte (2007) found that just imagining a pleasant experience, such as driving a car of a favorite brand, can increase the activity in the striatum, a brain area related to positive experience. The second study, by Plassmann, Kenning, \& Ahlert (2007) found that customers who are loyal to a store (e.g., H\&M vs. Zara), as measured by real purchasing behavior (i.e., amount spent, frequency and regency of purchases based on loyalty card data), show more activation in the striatum compared to customers who are less loyal, even if they are buying identical clothes. Experienced value is defined as the pleasure that derives from consuming a branded product (Plassmann, Ramsøy, \& Milosavljevic, 2012). According to Plassmann, Ramsøy, \& Milosavljevic (2012), the OFC (in particular its medial part) and other brain areas, such as the ventral striatum and the pregenual cingulate cortex, are active during positive product experience of a brand. The OFC is related to individual preferences for an aroma, music, and to secondary rewards such as money. Finally, memory is an important predictor of consumers' choices (Plassmann, Ramsøy, \& Milosavljevic, 2012). How we encode, consolidate, and retrieve brands define the remembered value. The remembered value consists of both explicit memory and implicit memory of prior consumption experience. It is possible to rely explicit memories, or declarative memories, on specific brain regions such as the hippocampus and surrounding medial temporal lobe (MTL) and dIPFC 
(Plassmann, Ramsøy, \& Milosavljevic, 2012). Another fMRI study show that these areas are related to successful encoding and subsequent recall (Klucharev, Smidts, \& Fernandez, 2008). Moreover, the researchers demonstrate a more direct activation of dlPFC and parahippocampal cortex. According to Plassmann, Ramsøy, \& Milosavljevic (2012), using neuroimaging data allows to track neural processes that predict conscious choice, such advances improve our understanding of implicit brand memory and studying the consumer psychology of branding.

Bartra, McGuire, \& Kable (2013) suggest that the study subjective value (SV) is an important factor in value-maximizing choice. SV allows to compare complex and qualitatively different choices on a common scale. In fact, assessing SV can be useful to predict consumers' preferences and behaviors over time and in different contexts. Numerous researchers try to identify neural signals associated with subjective value (SV). Bartra, McGuire, \& Kable (2013) tried to determine whether there are brain regions related to positive or negative SV. The results show that SV trigs two general patterns in the brain. Some brain regions showed both positively and negatively signed effects of SV across studies, while other regions showed positive effects only (Bartra, McGuire, $\&$ Kable, 2013). The occurence of SV effect, in vmPFC and PCC, is predominantly related to a positive effect; whereas activity in the dmPFC and bilateral anterior insula is related to a SV positive effect in some analysis and to SV negative effect in others (Bartra, McGuire, \& Kable, 2013). The authors also tried to determine whether the neural correlates of SV during decision-making are similar or different from SV responses during the receipt of an outcome (cf. "decision utility" vs. "experienced utility") (Kahneman et al., 1997). They found that a set of brain areas, including vmPFC and anterior VS, were positively related to signed effects. SV responses in these areas occur both during decision making and outcome delivery. Authors argued that there is evidence for reliable positive correlates of SV in VmPFC and anterior VS. These results suggest that VmPFC and VS form the core of a "valuation system" believed to play a critical role in value-based learning and decision-making. Such a signal theoretically is positioned to underlie value-maximizing choice.

Value maximization is an important concept to understand decision-making process. Determining how the value is perceived and experienced help researchers to study consumers' behaviors. As shown, Neuromarketing is a valuable tool for understanding the brain processes underlying expectancy and valuation during consumption.

\section{Neuromarketing and Marginal Utility: What Could Be Done}

Neuromarketing is an interdisciplinary and broad field of study. These relatively new research field is the union of two or more sciences, such as Marketing, Psychology, and Neurosciences. Neuromarketing research benefits mostly from the application of neuroimaging techniques to Marketing. The use of tools and theories from Neuroscience in Marketing is the main step to understand decision-making and related processes (Plassman et al., 2015). In fact, the most promising contribution that Neuromarketing can offer is a better understanding of consumers' behavior, individual differences, and prediction of marketing-relevant behavior. We found that there are several ways in which Neuroscience can aid Marketing and Consumer Behavior research. Specifically, it can be used to refine existing Marketing theories, improving the elements of Marketing-mix such as product, price, communication, and distribution policies (Kenning \& Linzmajer, 2010; Plassman et al., 2015). In particular, our findings suggested that NM is useful to improve product and brand policies. The application of NM, in the develop of a product, concerns both the initial stage of design process (testing prototypic ideas and concepts, developing the physical product; communicating product information) and the post design process (understanding user experience; segmenting consumers for effective Marketing; building models to predict consumer behavior) (Ariely \& Berns, 2010; Venkatraman et al., 2011). Moreover, Neuromarketing is useful to identify the components, both psychological and neural, that contribute to brand preferences (McClure et al., 2014). Neuroscience techniques, such as fMRI and EEG, can be used to understand how decision making is represented in the brain and how particular brands raise different brain responses. In particular, it is possible to measure changes in brain activity when familiar/unfamiliar brands are compared, to test brand loyalty or evaluate the effect of sustainability on consumers' decisions (Plassmann, Ramsøy, \& Milosavljevic, 2012; Pozharliev et al., 2015; Goucher-Lambert et al., 2016). Moreover, Neuromarketing research analyses the reward mechanisms and how consumers' asses chooses during the exposition to positive stimuli. Recent NM studies focused on the study of brain reward system (Breiter et al., 1997; Erk et al., 2002; Walter et al., 2005). Finally, the study of quality and value has significant and important implications for Marketing in order to determine customers' satisfaction. Neuromarketing research provides insights into the neural mechanism that we used to predict experience and remember quality and value of products or brand.

Taken together, these findings suggest that Neuromarketing not only can improve our understanding of decision-making process but also provide a completely new way to analyze consumers' buying behaviours. However, our literature review points out that there is no use of Marginal Utility theory in Neuromarketing research. Two critical issues are important to note. Firstly, MU theory is an important parameter in Economics and Marketing research. We hope that researchers and company to consider MU in Neuromarketing theory. 
Secondly, the use of MU can help to overcome some problems that affect Neuromarketing studies.

(1) Marginal Utility is an essential economic parameter that measures satisfaction, one of the most important elements of the consumer decision. We suggest that researchers must use Marginal Utility theory in order to measure customers' satisfaction. Customers' satisfaction is often seen as the key to a company's success and long-term competitiveness (Hennig-Thurau, \& Klee, 1997). Evaluating customers' satisfaction is important for different reasons. For instance, it is one of the strong determinant of consumers repurchase intention (Hellier, Geursen, Carr, \& Rickard, 2003). Consumer repurchase can be defined as "the individual's judgment about buying again a designated service from the same company, taking into accounts his or her current situation and likely circumstances" (Hellier, Geursen, Carr, \& Rickard, 2003). Measuring MU might help researchers to understand if products and services meet or exceed customers' expectations. Moreover, it can also be used to reduce customer churn (Gustafsson, Johnson, \& Roos, 2005). It gives us an indication of how likely a customer will make a purchase in the future. Measuring and tracking customer's satisfaction, can help companies in improving their business strategy and increasing the overall quality of customer service.

From an academic prospective, it can be used to improve and extend previous Marketing theories and Neuromarketing studies, such as Plassmann, Kenning, \& Ahler, (2007), on customer's loyalty. It is also a good parameter that allow to analyze how the consumer react to changing in the price. In fact, researches might measure changing in customer total satisfaction, reducing the quantity of a specific product, when the MU of the product is less that its price. Moreover, if we consider that MU measures the rate of change in utility when the quantity of a good consumed varies (Karaivanov, 2012), this parameter can be used in NM research to understand and evaluate how customers compare product.

(2) As discussed in section 4, Marginal Utility has not been well investigated in Neuroscience studies. We found that two studies examined the connection between underlying brain mechanism and MU theory. In particular, in the first study, authors analyzed the brain activity during a task performance by constructing predictor variables to explore the representation of undiscounted utility, the discount factor (the proportion by which utility is reduced in relation to an immediate payoff) and discounted utility (Pine et al., 2009). In the second study, Stauffer, Lak, \& Schultz (2014) investigated the connection between brain and neurotransmitters activity and the MU theory.

Our findings suggest that mostly of the experiments in Neuromarketing research considered Utility theory and value maximization. Some of the experiments suggest that it is possible to find neural signals associated with predicted values, experienced utility and subjective value (SV) of choice alternatives. However, to the best of our knowledge, no study to date has investigated the impact of MU on decision-making process in Neuromarketing research. We hope that researches to include MU as a parameter in Neuromarketing experiments. Following the previous studies, researches should try to develop a unified that model that describes human preferences integrating Marginal Utility. In this way, it might be possible to measure direct changes in Marginal Utility. It is also possible to test how individual differences or the gender influence MU. We found that, the most promising contribution that MU concept can offer to NM, is to better understanding the neural mechanism involved in decision-making process resulting from changes in utility associated with a small change for one of the goods consumed.

Moreover, researchers should consider the law of DMU. If the more of a good a person consumes, the less preference they will accord to having more of it (Brewer \& Venaik, 2009). It might be interesting to test brain reaction when customers are exposed to increasing quantity of the same item. We presume that it is possible to find significant difference in the brain activity when the customer reaches the saturation point. Finally, it might be possible to determine how the saturation point varies between individuals.

This calls for further research in this area.

\section{Conclusion and Future Directions}

This study concerns the impact of the Marginal Utility theory on Neuromarketing research on consumer behavior. Our review pointed out that there is no use of Marginal Utility theory in the new and innovative field research of Neuromarketing. This theory still now plays an important factor in the Marketing research, and in particular, in predicting consumers' choices and satisfaction, similarly to temperature for the predictions in physical phenomena (Raykov \& Calantone, 2014). On the other hand, consumer behavior, as a part of the human behavior, it is influenced also by objective factors, has a high subjective load, determined by cognitive and affective factors (Stroe \& Iliescu, 2104). Neuromarketing research, using neuroimaging tools, can easily measure and detect these factors. We suggest that Neuromarketing should focus on an interdisciplinary approach for providing a general overview of consumer's decision-making process and behavior using the MU theory. Future research in Neuromarketing might focus on the use of MU in order to determine customers' satisfaction and loyalty. Future 
studies could also focus on measuring reactions and behaviors of consumers when exposed to increasing quantity of the same item or evaluate if there is a correlation by brand, impulsivity and Marginal Utility.

\section{References}

Alvino, L., \& Franco, M. (2017). The decision-making process between rationality and emotions. International Journal of Scientific Research and Management, 5(9), 7074-7092. https://doi.org/10.18535/ijsrm/v5i9.18

Andrejevic, M. (2012). Brain whisperers: Cutting through the clutter with neuromarketing. Somatechnics, 2(2), 198-215. https://doi.org/10.3366/soma.2012.0057

Ariely, D., \& Berns, G. S. (2010). Neuromarketing: The hope and hype of neuroimaging in business. Nature Reviews Neuroscience, 11(4), 284-292. https://doi.org/10.1038/nrn2795

Balconi, M., Stumpo, B., \& Leanza, F. (2014). Advertising, brand and neuromarketing or how consumer brain works. Neuro Image, 16, 15-21. https://doi.org/10.7358/neur-2014-016-balc

Bartra, O., Mcguire, J. T., \& Kable, J. W. (2013). The valuation system: A coordinate-based meta-analysis of bold fMRI experiments examining neural correlates of subjective value. NeuroImage, 76, 412-427. https://doi.org/10.1016/j.neuroimage.2013.02.063

Beaver, J. D., Lawrence, A. D., Van Ditzhuljzen, J., Davis, M. H., Woods, An., \& Calder, A. J. (2006). Individual Differences in Reward Drive Predict Neural Responses to Images of Food. Journal of Neuroscience, 26(19), 5160-5166. https://doi.org/10.1523/JNEUROSCI.0350-06.2006

Bercea, M. D. (2012). Taking the pulse of the market: a consumer's decision-making algorithm using insights from neuromarketing research. In NeuroPsychoEconomics Conference proceedings.

Bernheim, B. D. (2009). On the potential of neuroeconomics: A critical (but hopeful) appraisal. American Economic Journal: Microeconomics, 1(2), 14977. https://doi.org/10.1257/mic.1.2.1

Bizer, G. Y., \& Schindler, R. M. (2005). Direct evidence of ending-digit drop-off in price information processing. Psychology \& Marketing, 22, 771-802. https://doi.org/10.1002/mar.20084

Boksem, M. A. S., \& Smidts, A. (2015). Brain responses to movie trailers predict individual preferences for movies and their population-wide commercial success. Journal of Marketing Research, 52(4), 482-492. https://doi.org/10.1509/jmr.13.0572

Breiter, H. C., Block, M., Blood, A. J., Calder, B., Chamberlain, L., Lee, N., ... Zhang, F. Z. (2014). Redefining neuromarketing as an integrated science of influence. Frontiers in Human Neuroscience, 8, 1073.

Brewer, P., \& Venaik, S. (2010). Globe practices and values: A case of diminishing Marginal Utility? Journal of International Business Studies, 41, 1316-1324. https://doi.org/10.1057/jibs.2010.23

Butler, M. J. R., O’Broin, H. L. R., Lee, N., \& Senior, C. (2016). How organizational Cognitive Neuroscience can deepen understanding of managerial decision-making: A review of the recent literature and future directions. International Journal of Management Reviews, 18(4), 542-559. https://doi.org/10.1111/ijmr.12071

Chand, S. (2016). Marginal Utility: What do you mean by Marginal Utility? Retrieved from http://www.yourarticlelibrary.com/economics/marginal-utility-what-do-you-mean-by-marginal-utility/3906 $5 /$

Christensen, L. R., Jorgenson, D. W., \& Lau, L. J. (1975). Transcendental logarithmic utility functions. American Economic Review, 65(3), 367-383.

Clithero, J. A., Tankersley, D., \& Huettel, S. A. (2008). Foundations of neuroeconomics: From philosophy to practice. PLoS Biology, 6(11), e298. https://doi.org/10.1371/journal.pbio.0060298

Cohen, A. J., King, H. B., \& Parkin, M. (2000). Household's choices. Part 3. In A. J. Cohen, H. B. King, \& M. Parkin (Eds.), Economics, Canada in the Global Environment (4th ed., Michael Parkin, Robin Bade. Study Guide). Ontario: Pearson Education.

Constantinides, E., \& Roth, V. (2015). The potential of neuromarketing as a marketing tool: Main topics and conceptual foundations, an introduction. European Marketing Academy Conference. Leuven, Belgium.

Daft, R. L., Murphy, J., \& Willmott, H. (2010). Organization theory and design. Boston: Cengage learning EMEA.

Damasio, A. R. (1994). Descartes Error: Emotion Reason, and the Human Brain. New York: Avonbooks. 
Diener, E. N. G., \& Tov, W. (2009). Balance in life and declining Marginal Utility of diverse resources. Applied Research Quality Life, 3, 277-291. https://doi.org/10.1007/s11482-009-9062-1

Dittmer, T. (2005). Diminishing Marginal Utility in economics textbooks. The Journal of Economic Education, 36(4), 391-399. https://doi.org/10.3200/JECE.36.4.391-399

Dooley, R. (2007). Marginal marketing. Retrieved from http://www.neurosciencemarketing.com/blog/articles/marginal-marketing.htm

Erk, S., Spitzer, M., Wunderlich, A. P., \& Galley, L. H. (2002). Cultural objects modulate reward circuitry. Neuroreport, 13, 2499-2503. https://doi.org/10.1097/00001756-200212200-00024

Falk, E. B., Berkman, E. T., \& Lieberman, M. D. (2012). From neural responses to population behavior: Neural focus group predicts population-level media effects. Psychological Science, 23(5), 439-445. https://doi.org/10.1177/0956797611434964

Fisher, C. E, Chin, L., \& Klitzman, R. (2010). Defining neuromarketing: practices and professional challenges. Harvard Review of Psychiatry, 18(4), 230-237. https://doi.org/10.3109/10673229.2010.496623

Fortunato, V. C. R., Giraldi, J. E., \& De Olivera, J. H. C. (2014). A review of studies on neuromarketing: practical results, techniques, contributions and limitations. Journal of Management Research, 6(2), 201-220. https://doi.org/10.5296/jmr.v6i2.5446

Frijtersa, P., \& Leighb, A. (2008). Materialism on the march: From conspicuous leisure to conspicuous consumption? The Journal of Socio-Economics, 37, 1937-1945. https://doi.org/10.1016/j.socec.2008.07.004

Frisch, R. (1932). New methods of measuring Marginal Utility. The Economic Journal, 42, 252-256. https://doi.org/10.2307/2223823

Fugate, D., 2008, Marketing services more effectively with neuromarketing research: A look into the future. Journal of Services Marketing, 22(2), 170-173. https://doi.org/10.1108/08876040810862903

Galiani, F. (1751). Della moneta. Reprinted in: Collezioni Custodi Scrittori Classici Italiani di Economia Politica, 10.

Gossen, H. H. (1983). The Laws of Human Relations and the Rules of Human Action Derived Therefrom. Cambridge: MIT Press.

Goucher-Lambert, K., Moss, J., \& Cagan, J. (2016). Inside the mind: Using neuroimaging to understand moral product preference judgments involving sustainability. Journal of Mechanical Design, 139(4), 041103-11. https://doi.org/10.1115/1.4035859

Gustafsson, A., Johnson, M. D., \& Roos, I. (2005). The effects of customer satisfaction, relationship commitment dimensions, and triggers on customer retention. Journal of Marketing, 69(4), 210-218. https://doi.org/10.1509/jmkg.2005.69.4.210

Hannah, S. T., Balthazard, P. A., Waldman, D. A., Jennings, P. L., \& Thatcher, R. W. (2013). The psychological and neurological bases of leader self-complexity and effects on adaptive decision-making. Journal of Applied Psychology, 98(3), 393. https://doi.org/10.1037/a0032257

Hellier, P. K., Geursen, G. M., Carr, R. A., \& Rickard, J. A. (2003). Customer repurchase intention: A general structural equation model. European Journal of Marketing, 37(11/12), 1762-1800. https://doi.org/10.1108/03090560310495456

Hennig-Thurau, T., \& Klee, A. (1997). The impact of customer satisfaction and relationship quality on customer retention: A critical reassessment and model development. Psychology \& Marketing, 14(8), 737-764. https://doi.org/10.1002/(SICI)1520-6793(199712)14:8<737::AID-MAR2>3.0.CO;2-F

Kable, J. W., \& Glimcher, P. W. (2007). The neural correlates of subjective value during intertemporal choice. Nature Neuroscience, 10, 1625-1633. https://doi.org/10.1038/nn2007

Karaivanov, A. (2012). Marginal Utility and MRS (detailed notes). Retrieved from http://www.sfu.ca/akaraiva/mrsnotes.pdf

Kauder, E. (1953). Genesis of the Marginal Utility theory: From Aristotle to the end of the eighteenth century. The Economic Journal, 63, 638-650. https://doi.org/10.2307/2226451

Keller, K. L. (2008). Strategic brand management: building, measuring, and managing brand equity (3rd ed.). NJ: Pearson/Prentice Hall. 
Kenning, P., \& Linzmajer, M. (2010). Consumer neuroscience: An overview of an emerging discipline with implications for consumer policy. Journal of Consumer Protection and Food Safety, 6, 111-125. https://doi.org/10.1007/s00003-010-0652-5

Kim, S., Hwang, J., \& Lee, D. (2008). Prefrontal coding of temporally discounted values during intertemporal choice. Neuron, 59, 161-172. https://doi.org/10.1016/j.neuron.2008.05.010

Kishtainy, N., Abbot, G., Farndon, J., Kennedy, F., Meadway, J., Wallace, C., \& Weeks, M. (2012). The economic book. Big ideas simply explained: First American Edition. New York: DK Publishing.

Klucharev, V., Smidts, A., \& Fernandez, G. (2008). Brain mechanisms of persuasion: How expert power modulates memory and attitudes. Social Cognitive and Affective Neuroscience, 3(4), 353-366. https://doi.org/10.1093/scan/nsn022

Knutson, B., Rick, S., Wimmer, G. E., Prelec, D., \& Loewenstein, G. (2007). Neural predictors of purchases. Neuron, 53(1), 147-156. https://doi.org/10.1016/j.neuron.2006.11.010

Kobayashi, S., \& Schultz, W. (2008). Influence of reward delays on responses of dopamine neurons. Journal of Neuroscience, 28, 7837-7846. https://doi.org/10.1523/JNEUROSCI.1600-08.2008

Koc, E., \& Boz, H. (2014). Psychoneurobiochemistry of tourism marketing. Tourism Management, 44, 140-148. https://doi.org/10.1016/j.tourman.2014.03.002

Koutsoyiannis, A. (1979). Modern Microeconomics. London: Press LTD. https://doi.org/10.1007/9781349160778

Lee, N., Broderick, A. J., \& Chamberlain, L. (2006). What is neuromarketing? A discussion and agenda for future research. International Journal of Psychophysiology, 63(2), 199-204. https://doi.org/10.1016/j.ijpsycho.2006.03.007

Lee, N., Senior, C., \& Butler, Jr. (2012). The domain of organizational cognitive neuroscience: Theoretical and empirical challenges. Journal of Management, 38(4), 921-931. https://doi.org/10.1177/0149206312439471

Lehrer, J. (2007). Can economic utility be measured?. Retrieved from http://scienceblogs.com/cortex/2007/04/08/can-economic-utility-be-measur-1/

Levallois, C., Clithero, J. A., Wouters, P., Smidts, A., \& Huettel, S. A. (2012). Translating upwards: Linking the neural and social sciences via Neuroeconomics. Nature Reviews Neuroscience, 13(11), 789-797. https://doi.org/10.1038/nrn3354

Liat, C. B., Mansori, S., Chuan, C. G., \& Imrie, B. C. (2017). Hotel service recovery and service quality: Influences of corporate image and generational differences in the relationship between customer satisfaction and loyalty. Journal of Global Marketing, 30(1), 42-51. https://doi.org/10.1080/08911762.2016.1262932

Lindstrom, M. (2008). Buyology. Truth and lies about why we buy. New York: Crown Publishing Group.

March, J. G. (1998). Prendere Decisioni. Bologna: Il Mulino.

Marshall, A. (1890). Principles of Economics. London: Press LTD.

Mcclure, S., Li, J., Tomlin, D., Cypert, K., Montague, L., \& Montague, R. (2014). Neural correlates of behavioral preference for culturally familiar drinks. Journal of Neuron, 44, 379-387. https://doi.org/10.1016/j.neuron.2004.09.019

Miljkovic, M., \& Alcakovic, S. (2010). Neuromarketing: Marketing Research Future?. Singidunum Revija, 7(2), 273-283.

Mill, J. S. (1848). Principles of Political Economy with some of their applications to social philosophy. London: John W. Parker.

Mobini, S., Body, S., Ho, M. Y., Bradshaw, C. M., Szabadi, E., Deakin, J. F., \& Anderson I. M. (2002). Effects of lesions of the orbitofrontal cortex on sensitivity to delayed and probabilistic reinforcement. Psychopharmacology, 160, 290-298. https://doi.org/10.1007/s00213-001-0983-0

Murugappan, M., Murugappan, S., \& Gerard, C. (2014). Wireless EEG signals based neuromarketing system using Fast Fourier Transform (FFT). Signal Processing \& its Applications (CSPA), 2014 IEEE 10th International Colloquium on IEEE: 25-30. 
Nakamura, R., Miura, H., Matsuda, N., \& Taki, H. (2016). Analysis of the cerebral blood flow affected by brand impressions of the products. Procedia Computer Science, 96, 1748-1755. https://doi.org/10.1016/j.procs.2016.08.223

Naranjo, C. A., Tremblay, L. K., \& Busto, U. E. (2001). The role of the brain reward system in depression. Progress in Neuro-Psychopharmacology \& Biological Psychiatry, 25(4), 781-823. https://doi.org/10.1016/S0278-5846(01)00156-7

Padoa-Schioppa, C., \& Assad, J. A. (2006). Neurons in the orbitofrontal cortex encode economic value. Nature, 441, 223-226. https://doi.org/10.1038/nature04676

Pine, A., Seymour, B., Roiser, J. P., Bossaerts, P., Friston, K. J., Curran, H. V., \& Dolan, R. J. (2009). Encoding of Marginal Utility across time in the human brain. The Journal of Neuroscience, 29, 9575-9581. https://doi.org/10.1523/JNEUROSCI.1126-09.2009

Plassmann, H., \& Weber, B. (2015). Individual differences in marketing placebo effects evidence from brain imaging and behavioral experiment. Journal of Marketing Research, 52(4), 493-510. https://doi.org/10.1509/jmr.13.0613

Plassmann, H., O'doherty, J., \& Rangel, A. (2007). Orbitofrontal cortex encodes willingness to pay in everyday economic transactions. Journal of Neuroscience, 27(37), 9984-9988. https://doi.org/10.1523/JNEUROSCI.2131-07.2007

Plassmann, H., O'doherty, J., Shiv, B., \& Rangel, A. (2008). Marketing actions can modulate neural representations of experienced pleasantness. Proceedings of the National Academy of Sciences of the United States of America, 105(3), 1050-1054. https://doi.org/10.1073/pnas.0706929105

Plassmann, H., Ramsoy, T. Z., \& Milosavljevic, M. (2012). Branding the brain: A critical review and outlook. Journal of Consumer Psychology, 22, 18-36. https://doi.org/10.1016/j.jcps.2011.11.010

Plassmann, H., Venkatraman, V., Huettel, S., \& Yoon, C. (2015). Consumer neuroscience: Applications, challenges, and possible solutions. Journal of Marketing Research, 52, 427-435. https://doi.org/10.1509/jmr.14.0048

Platt, M. L., \& Glimcher, P. W. (1999). Neural correlates of decision variables in parietal cortex. Nature, 400, 233-238. https://doi.org/10.1038/22268

Pozharliev, R., Verbeke, W. J. M. I, Van Strien, J. W., \& Bagozzi, R. P. (2015). Merely being with you increases my attention to luxury products: Using EEG to understand consumers emotional experience with luxury branded products. Journal of Marketing Research, 52(4), 546-558. https://doi.org/10.1509/jmr.13.0560

Ravald, A., \& Gronroos, C. (1996). The value concept and relationship marketing. European Journal of Marketing, 30(2), 19-30. https://doi.org/10.1108/03090569610106626

Raykov, T., \& Calantone, R. J. (2014). The utility of item response modelling in marketing research. Journal of the Academy of Marketing Science, 42, 337-360. https://doi.org/10.1007/s11747-014-0391-8

Reimann, M., Zaichkowsky, J., Neuhaus, C., Bender, T., \& Singh, B. W. (2010). Aesthetic package design: a behavioral, neural, and psychological investigation. Journal of Consumer Psychology, 20, 431-441. https://doi.org/10.1016/j.jcps.2010.06.009

Rothbard, M. N. (1997). Toward a Reconstruction of Utility and Welfare Economics. In N. Murray (Ed.), The Logic of Action One: Method, Money, and the Austrian School. London: Edward Elgar.

Russo, V. (2015). Neuromarketing, comunicazione e comportamenti di consumo. Principi, strumenti e applicazioni nel food and wine. Milan: Franco Angeli

Salvatore. (2008). Consumer preferences and choice. Chapter 3.

Samuelson, P. A. (1937). A note on measurement of utility. The Review of Economic Studies, 4, 151-161. https://doi.org/10.2307/2967612

Sanfey, A. G., Loewenstein, G., Mcclure, S. M., \& Cohen, J. D. (2006), Neuroeconomics: cross-currents in research on decision making. TRENDS in Cognitive Sciences, 10(3), 108-116. https://doi.org/10.1016/j.tics.2006.01.009

Sanfey, A. G., Rilling, J. K., Aronson, J. A., Nystrom, L. E., \& Cohen, J. D. (2003). The neural basis of economic decision-making in the ultimatum game. Science, 300, 1755-1758. https://doi.org/10.1126/science.1082976 
Schaefer, M., \& Rotte, M. (2007). Thinking on luxury or pragmatic brand products: Brain responses to different categories of culturally based brands. Brain Research, 1165, 98-104. https://doi.org/10.1016/j.brainres.2007.06.038

Schultz, W. (2016). Dopamine reward prediction error coding. Dialogues in Clinical Neuroscience, 18(1), 23-32.

Schultz, W., \& Dickinson, A. (2000). Neuronal coding of prediction errors. Annual Review of Neuroscience, 23(1), 473-500. https://doi.org/10.1146/annurev.neuro.23.1.473

Schweinhardt, P., Seminowicz, D. A., Jaeger, E., Duncan, G. H., \& Bushnell, M. C. (2009). The Anatomy of the Mesolimbic Reward System: A Link between Personality and the Placebo Analgesic Response. Journal of Neuroscience, 29(15), 4882-4887. https://doi.org/10.1523/JNEUROSCI.5634-08.2009

Singh, J. (2016). Consumer's behaviour: Cardinal utility analysis (explained with diagram). Retrieved from $\mathrm{http} / / / \mathrm{www}$.economicsdiscussion.net/cardinal-utility-analysis/consumers-behaviour-cardinal-utility-analysis -explained-with-diagram/1111

Smith, A. (1776). La ricchezza delle nazioni. Milan: Isedi.

Stauffer, W. R., Lak, A., \& Schultz, W. (2014). Dopamine reward prediction error responses reflect Marginal Utility. Current Biology, 24, 2491-2500. https://doi.org/10.1016/j.cub.2014.08.064

Stroe, M. A., \& Iliescu, E. M. (2014). Interdisciplinary perspectives on individual consumption. Challenges of the Knowledge Society, 1, 579-585.

Swaminathan, N. (2007). Money talks: A brain image of a microeconomic theory. Retrieved from https://www.scientificamerican.com/article/microeconomic-theory-in-the-brain/

Sylos-Labini, P. (1982). Lezioni di Economia, Volume II, Parte Quinta: Un modello dinamico. Roma: Ed. Ateneo.

Tobler, P. N., Fletcher, P. C., Bullmore, E. T., \& Schultz, W. (2007). Learning-related human brain activations reflecting individual finances. Neuron, 54, 167-175. https://doi.org/10.1016/j.neuron.2007.03.004

Tosi, L. H., Pilati, M., Mero Neal, P., \& Rizzo, J. R. (2002). Comportamento Organizzativo. Persone, Gruppi e Organizzazioni. Milan: Egea.

Varian, H. R. (2002). Microeconomia (5th ed.). Venezia: Libreria Editrice Cafoscarina.

Venkatraman, V., Clithero, J. A., Fitzsimons, G. J., \& Huettel, S. A. (2012). New scanner data for brand marketers: How neuroscience can help better understand differences in brand preferences. Journal of Consumer Psychology, 22, 143-153. https://doi.org/10.1016/j.jcps.2011.11.008

Vlasceanu, S. (2014). New directions in understanding the decision-making process: neuroeconomics and neuromarketing. Procedia-Social and Behavioral Sciences, 127, 758-762. https://doi.org/10.1016/j.sbspro.2014.03.350

Von Neumann, J., \& Morgenstern, O. (1947). Theory of games and economic behavior (2nd ed.). New Jersey: Princeton University Press.

Walter, H., Abler, B., Ciaramidaro, A., \& Erk, S. (2005). Motivating forces of human actions: neuroimaging reward and social interaction. Brain Research Bulletin, 67, 368-381. https://doi.org/10.1016/j.brainresbull.2005.06.016

Wise, R. A., \& Rompre, P. P. (1989). Brain dopamine and reward. Annual Review of Psychology, 40(1), 191-225. https://doi.org/10.1146/annurev.ps.40.020189.001203

\section{Copyrights}

Copyright for this article is retained by the author, with first publication rights granted to the journal.

This is an open-access article distributed under the terms and conditions of the Creative Commons Attribution license (http://creativecommons.org/licenses/by/4.0/). 